\title{
Accounting
}

\section{A new method to measure production spoilage and its effect on cost reduction}

\author{
Mohammad AL-Dahiyat ${ }^{a^{*}}$, Ismail AL-Tkryty a and Bassam Jaara ${ }^{a}$
}

${ }^{a}$ AL-Ahliyya Amman University, Jordan

\section{H R O N I C L E}

Article history:

Received: October 30, 2020

Received in revised format:

November 302020

Accepted: December 30, 2020

Available online:

December 30, 2020

Keywords:

Production spoilage

Production cost

Cost management

Cost reduction

Innovative cost method

\begin{abstract}
A B S T R A C T
The current study proposes a new method to account for production spoilage in process costing system, not previously discussed in cost accounting literature and/or textbooks. It differs from traditional methods discussed in cost accounting textbooks in determining normal spoilage units and assignment of production cost. The study used data from a real factory that makes men's suits for January 2018 to illustrate and explain the proposed method and its impact on cost reduction. The obtained results prove the study proposition that traditional methods to account for production spoilage overstate normal spoilage cost, and hides or understate actual abnormal spoilage. The proposed method reduced normal spoilage cost by $27 \%$, compared to traditional methods. Thus, the significant reduction in normal spoilage resulted also in a cost reduction of good units manufactured. In addition, the abnormal spoilage cost under the proposed method increased by $35 \%$ thus, it would be noticeable by management to focus on, control and eliminate. The study recommends that manufacturing firms adopt the proposed method to account for production spoilage as it is more accurate and helps management focus on production spoilage and take corrective actions to control and eliminate.
\end{abstract}

\section{Introduction}

Given the developments in the manufacturing sector and its importance in the economy, and in the light of the challenges and competition this sector encounters, more innovative practices and methods are needed to enhance its competitiveness and contribution in the economy (Melendez, Davial \& Melgar, 2019; Dereli, 2015; Hervas \& Dalmau, 2006). In addition, its argued that contemporary changes and challenges in manufacturing environment have caused the traditional cost accounting systems to be less relevant and reliable and posed pressure on cost accounting to adapt or change traditional costing methods and develop innovative methods and systems in order to support manufacturers' cost reduction efforts and competitiveness ( Johnson and Kaplan, 1987; Lukka \& Granlund, 1996; Oker, 2002; Wang \& Yuan, 2009; Gracanin et al., 2014; Abdusalomova, 2017). In this context, innovation refers to an idea, method, technique, system or practice that is perceived as new by individual or the adoption firm (Damanpur \& Gopalakrishnan, 1998; Rogers, 2003; Askarani, 2015).

Production spoilage cost, resulting from poor production quality, has become a major challenge facing manufacturing firms and hinders manufacturers' ability to increase their competitiveness. These costs range from $16.91 \%$ to $26.90 \%$ of company revenue, and normally remain hidden from management and buried in the accounting figures (Mahmood \& Kureshi, 2015). Firms need to improve production quality, highlight, manage, control and eliminate production spoilage by properly account for production spoilage to enhance their competitiveness (Malta \& Cunha, 2011; Pike, Tayles \& Mansor, 2011). The existing traditional cost accounting systems are unable to measure and report 'the true costs' of production spoilage and poor internal quality costs (Evans \& Lindsay, 2005; Rao, et. al., 2010; Mahmood \& Kureshi, 2015).

* Corresponding author.

E-mail address: mohamaddahiyat@gmail.com (M. AL-Dahiyat) 
Spoilage is units of production, whether fully or partially completed, that are discarded because they do not meet specifications required by customers and result in material and labor wastage (Horngren, Datar \& Rajan, 2012, p. 667). Accounting for production spoilage costs is important in terms of determining the normal and abnormal spoilage costs and in terms of cost management and control. Normal spoilage represents a certain determined amount of spoilage that is inherent in some production processes. Normal Spoilage is normally determined as a percentage of good units manufactured and its cost is normally buried in cost of good units manufactured. Hence, the cost of good units increases or decreases, as a result of an increase or decrease in the amount of normal spoilage. However, if a manufacturing firm target is to reach $100 \%$ of good units manufactured, then any spoilage is considered as abnormal. Abnormal spoilage, arise in poor quality manufacturing conditions since it is not inherent in the production process, thus its cost would disappear if the job is done right the first time (Mahmood \& Kureshi, 2015). Abnormal spoilage is considered a spoilage loss recognized in the income statement.

As were indicated earlier, accounting for production spoilage in the process costing system is of great importance to enhance cost reduction and competitiveness of manufacturing firms. However, spoilage cost mostly remains hidden because existing traditional costing systems are unable to measure and report 'the true costs' of production spoilage. Therefore, there is a need for more innovative cost accounting practices and methods to account for production spoilage. Accounting literature and research on production spoilage and innovative and novel cost accounting ideas and methods are rare and require further research (Zawawi \& Hough, 2010; Mahmood \& Qureshi, 2015). This, has provided the motivation for conducting the current study.

\section{Study Problem and Proposition}

There are several methods in the literature to account for production spoilage (Horngren et al., 2012; Drury, 2018). Commonly, firms ignore production spoilage, regardless it is normal or abnormal, and consider all manufacturing costs as good units manufactured cost. Ignoring production spoilage if it occurs overstates product cost, thus, firms will have to sell its products at higher than the market prices to recover costs or at the market prices and here the firm will either lose its market share or accept lower profit margins. Normally firms account for production spoilage by considering normal spoilage as a component of good units manufactured costs, on the bases that good units cannot be made without also making some spoiled units (Horngren et al., 2012, p. 668).

The current study proposition is that accounting for normal and abnormal spoilage is of great importance to enhance cost reduction and competitiveness of manufacturing firms. Traditional methods suggested in the cost accounting literature to account for production spoilage either overstate normal spoilage cost and/or hides or understate actual abnormal production spoilage. Overstating the value of the normal spoilage results in overstating the costs of good units completed and hides or understate the true value of abnormal spoilage (Kolus, Wells \& Neumann, 2018). In addition, abnormal spoilage is supposed not to occur in a healthy and efficient manufacturing environment and if it occurs it should be not be hidden or understated so that management is aware of its significance, causes and responsibility centers accountable for, thus, take proper actions to control and eliminate it in future.

The current study proposes a new method, not previously discussed in the literature, to overcome deficiencies in traditional methods and account for production spoilage in a reliable way that would reduce good units manufactured costs, thus, enhance the competitiveness and growth of the manufacturing firms. In other words, the proposed method overcomes deficiencies in traditional methods by not overstating normal spoilage nor hiding or understating abnormal spoilage. This would realistically result in product cost reduction and thus, enhances the competitiveness of the firm. The study proposition will be tested through a practical illustration based on a real manufacturing case study, pertinent to one of the factories for men' suits, the researchers participated in to understand and solve the deterioration of its competitiveness in the market.

\subsection{Importance of the Study}

The significance of the study was implicitly indicated earlier but will be explicitly emphasized and reiterated here. The current study contributes to the cost accounting innovation literature pertinent to accounting for production spoilage and manufacturing cost reduction. The study proposes a new method, not previously discussed in the literature, to account for production spoilage in a way that would reduce good units manufactured costs. In addition, the proposed method overcomes deficiencies in traditional methods by not overstating normal spoilage nor hiding or understating abnormal spoilage. This would realistically result in product cost reduction and thus, enhances the competitiveness of manufacturing firms. 


\subsection{Practical Illustration of the traditional methods and Proposed Method to Account for Spoilage}

The current section of the study will illustrate and explain accounting for production spoilage under the proposed and the traditional methods of process costing methods. The results obtained from these methods will be compared and discussed in section 3 .

\section{The Case Study}

The suits factory understudy was established at the beginning of eighties of the last century and enjoyed a good reputation in the market for its high quality and fashionable suits. However, recently the competitiveness of the suits' factory has suffered partly due to the intense competition and high uncertainty in the business environment, and partly due to high production costs and prices compared to similar imported suits. To assist the suits factory to regain its competitiveness in the market, the researchers studied the production processes in the factory and found that weighted average cost flow method of process costing is used to account for production cost. The researchers found that the factory does not account for production spoilage, whether normal or abnormal spoilage. In other words, all spoilage cost is added to good units manufactured cost. This practice has contributed to increasing the cost of good units of production, and accordingly the selling price of their suits, hence, deteriorating the competitiveness of the company in the market, since customers are searching for a quality product with the lowest cost.

The making process of the suits consists of two processes or stages. In the first process, the measurements and cuts of the fabric of the suit according to sizes and models take place. At this stage, the fabric/cloth is used in addition to the direct labor and other conversion costs. Then the suit's fabric at the end of the first process is transferred to the second process, the sewing and finishing stage. All production costs incurred in the first stage is transferred to the second process and the cost at the end of the second stage will be cumulative for both phases. At this stage, the fabric is converted into finished suits by professional tailors. Threads, linings, blowing and buttons are used in this stage and this stage is considered the primary stage where production spoilage costs and good suit cost is determined. The fabric/cloth is added at the beginning of the process, threads added evenly during the process, lining added when the product reaches to $50 \%$ completion level, blowing added when the product reaches to $70 \%$, and the buttons used at the end of the process. Labor and other expenses (conversion cost) are used evenly throughout the process. Production spoilage is detected at the inspection point when production process reaches $50 \%$ of completion. The following production data, presented in Table 1 and Table 2, relates to the suits factory (sewing and finishing department) for January 2018 production.

\section{Table 1}

\section{Production data for the month of January 2018}

\begin{tabular}{ll}
\hline Units started during the period & 520 suits \\
Work in process, beginning inventory (January 1) & 80 suits (completion $75 \%$ of conversion cost) \\
Second work in process, beginning inventory & 50 suits (completion $50 \%$ of conversion cost) \\
Suits completed during the period & 460 suits \\
Work in process, ending inventory (January 31) & 80 (completion $25 \%$ of conversion cost) \\
Second Work in process, ending (January 31) & 60 suits (completion $75 \%$ of conversion cost) \\
Normal spoilage (Inspection at 50\% completion level) & Estimated at 5\% of good finished suits \\
\hline
\end{tabular}

Table 2

Production cost data for the month of January 2018

\begin{tabular}{|c|c|c|c|c|c|c|c|c|}
\hline & Cloth & Threads & Lining & Blowing & Buttons & Labor & Expenses & Total \\
\hline WIP $1 / 1(75 \%)$ & $\$ 3,520$ & $\$ 230$ & $\$ 264$ & $\$ 260$ & --------- & $\$ 2,029$ & $\$ 1,036$ & $\$ 7,339$ \\
\hline WIP $1 / 1(50 \%)$ & 1,224 & 60 & 136 & --------- & ---------- & 1,120 & 810 & 3,350 \\
\hline Current period & 18,200 & 2,325 & 1,760 & 1,320 & 1,840 & 23,250 & 13,950 & 62,645 \\
\hline Cost to account & 22,944 & 2,615 & 2,160 & 1,580 & 1,840 & 26,399 & 15,796 & 73,334 \\
\hline
\end{tabular}

Based on the above data, production costs and accounting for spoilage under traditional and proposed methods are presented next. The traditional methods to account for spoilage under weighted average and FIFO cost flow methods are illustrated first and then the proposed method is explained and illustrated. The five-step procedure for process costing is followed to illustrate each method (Horngren et al., 2012, p. 670).

\subsection{Illustration of traditional methods to account for production spoilage}

\subsubsection{Traditional Weighted Average Method (Ignoring Spoilage)}

This method is used in the suits factory understudy and is also commonly used in similar local factories due to its simplicity. Under this method, all spoilage costs are added to finished suites production cost regardless it is normal or abnormal spoilage. This method contributes to increasing the cost of good units finished and completed, thus, the price of these products will be overstated to cover increased product cost. Table 3 presents the first step of process costing and summarizes the flow of physical units and output. It can be noted that the output units to account for is less than input units by 50 units which are considered as production spoilage or damaged units not accounted for by this factory. 
Table 3

Output in physical units traditional under weighted average method (ignoring spoilage)

\begin{tabular}{lr}
\hline Work in process, beginning inventory $1 / 1($ level $75 \%)$ & 80 suits \\
WIP inventory $1 / 1$ (completion level $50 \%)$ & 50 suits \\
Suits started during the period & 520 suits \\
Input units to account for & 650 suits \\
Suits completed during the period & 460 suits \\
WIP ending inventory $31 / 1$ (completion level $25 \%)$ & 80 suites \\
WIP ending inventory (completion level $75 \%)$ & 60 suites \\
Output units to account for & 600 suits
\end{tabular}

Table 4

Equivalent units under traditional weighted average method (ignoring spoilage)

\begin{tabular}{lccccccc}
\hline & Cloth & threads & Lining & Blowing & Buttons & Labor & Expenses \\
\hline Units completed & 460 & 460 & 460 & 460 & 460 & 460 & 460 \\
WIP 31/1 (25\%) & 80 & 20 & ---- & ---- & --- & 20 & 45 \\
WIP 31/1 (75\%) & 60 & 45 & 60 & 60 & ---- & 45 \\
\hline Total & 600 & 525 & 520 & 520 & 460 & 525 \\
\hline
\end{tabular}

The third step of process costing summarizes total cost to account for and the fourth step calculates cost per equivalent unit are presented in Table 5.

Table 5

Cost to account for and the cost per unit under traditional weighted average method (ignore spoilage)

\begin{tabular}{|c|c|c|c|c|c|c|c|c|}
\hline & Cloth & Threads & Lining & Blowing & Buttons & Labor & Expenses & Total \\
\hline WIP 1/1 (75\%) & $\$ 3520$ & $\$ 230$ & $\$ 264$ & $\$ 260$ & ------ & $\$ 2029$ & $\$ 1036$ & $\$ 7339$ \\
\hline WIP 1/1 (50\%) & 1224 & 60 & 136 & ---------- & ------- & 1120 & 810 & 3350 \\
\hline Current cost & $\$ 18200$ & 2325 & 1760 & 1320 & 1840 & 23250 & 13950 & 62645 \\
\hline $\begin{array}{l}\text { Cost to account/ equiv. } \\
\text { units } \\
\text { Cost per unit }\end{array}$ & $\begin{array}{l}22,944 / \\
600= \\
\$ 38.24\end{array}$ & $\begin{array}{l}2615 / \\
525= \\
\$ 4.98\end{array}$ & $\begin{array}{l}2160 / \\
520= \\
\$ 4.15\end{array}$ & $\begin{array}{l}1580 / \\
520= \\
\$ 3.04\end{array}$ & $\begin{array}{l}1840 / \\
460= \\
\$ 4.00\end{array}$ & $\begin{array}{l}26399 / \\
525= \\
\$ 50.28\end{array}$ & $\begin{array}{l}15796 / \\
525= \\
\$ 30.09\end{array}$ & $\begin{array}{l}73,334 \\
\$ 134.78 \\
\end{array}$ \\
\hline
\end{tabular}

Finally, Table 6 presents the fifth step of process costing related to assigning total costs to units completed, to spoiled units (ignored in this method) and ending inventory work in process (WIP ending).

Table 6

Assignment of production cost under traditional weighted average method (ignore spoilage)

\begin{tabular}{|c|c|c|c|c|c|c|c|c|}
\hline & Cloth & Threads & Lining & Blowing & Buttons & Labor & Expenses & Total \\
\hline Units completed & & & & & & & & $\$ 61,998.80 *$ \\
\hline WIP $31 / 1(25 \%)$ & $80 \times 38.24$ & $20 \times 4.98$ & --------- & --------- & ------- & $20 \times 50.28$ & $20 \times 30.09$ & $\$ 4766.20$ \\
\hline WIP $31 / 1(75 \%)$ & $60 \times 38.24$ & $45 \times 4.98$ & $60 \times 4.15$ & $60 \times 3.04$ & ------- & $45 \times 50.28$ & $45 \times 30.09$ & $\$ 6566.55$ \\
\hline Total cost & & & & & & & & $\$ 73,331.55$ \\
\hline
\end{tabular}

$*$ Total cost of good units completed $=460 \times \$ 134.78=\$ 61,998.80$.

(Any differences in figures are due to rounding figures).

\subsubsection{Traditional Weighted Average Method and Spoilage}

This method accounts for production spoilage. The normal spoilage units are counted when computing physical and equivalent units of output. It is also worth mentioning here, that spoiled units are counted at the stage of completion where the inspection takes place. In our illustration case, inspection is done at the stage of $50 \%$ completion level. The formula to determine normal spoilage as follows:

$$
\begin{aligned}
& \text { Normal spoilage units }=\text { good production units } \mathrm{x} \text { normal spoilage percentage } \\
& \text { Good production units }=\text { good units completed }+ \text { ending work in process (WIP) passed inspection }
\end{aligned}
$$

Its noteworthy to mention that this method assign normal spoilage cost to good units completed and ending WIP passed inspection only while ending WIP units not reached inspection were not assigned normal spoilage costs on the bases that they will be detected as spoiled when inspected in the subsequent accounting period and assigned costs of normal spoilage when completed at that time. However, a disadvantage of this method, as well as in other traditional methods, is that it ignores the beginning WIP unit's level of completion, and includes all units of beginning WIP for determining normal spoilage in the current period. Thus, normal spoilage units will be inaccurate and inflated. In other words, the units of normal spoilage will be overstated if beginning WIP has reached and passed the inspection level in the prior period. The beginning WIP passed inspection point in the prior period should be excluded from the computation of normal spoilage in the current period on the grounds that it was counted for as ending inventory passed inspection in the prior period. This point will be further discussed later in subsection 2.3 when discussing the proposed method. The five-step procedure for process costing, with slight modifications to accommodate normal and abnormal spoilage under this method is illustrated and presented in the following tables. Table 7 and Table 8 present step 1 and 2 , for 
determining physical output and equivalent units. Steps $3 \& 4$ for determining costs to account for and cost per unit are illustrated in Table 9 below. While, Table 10 presents assigning total costs to units completed, spoiled units and ending work in process (WIP 31/1).

\section{Table 7}

Output in physical units under traditional weighted average method and spoilage

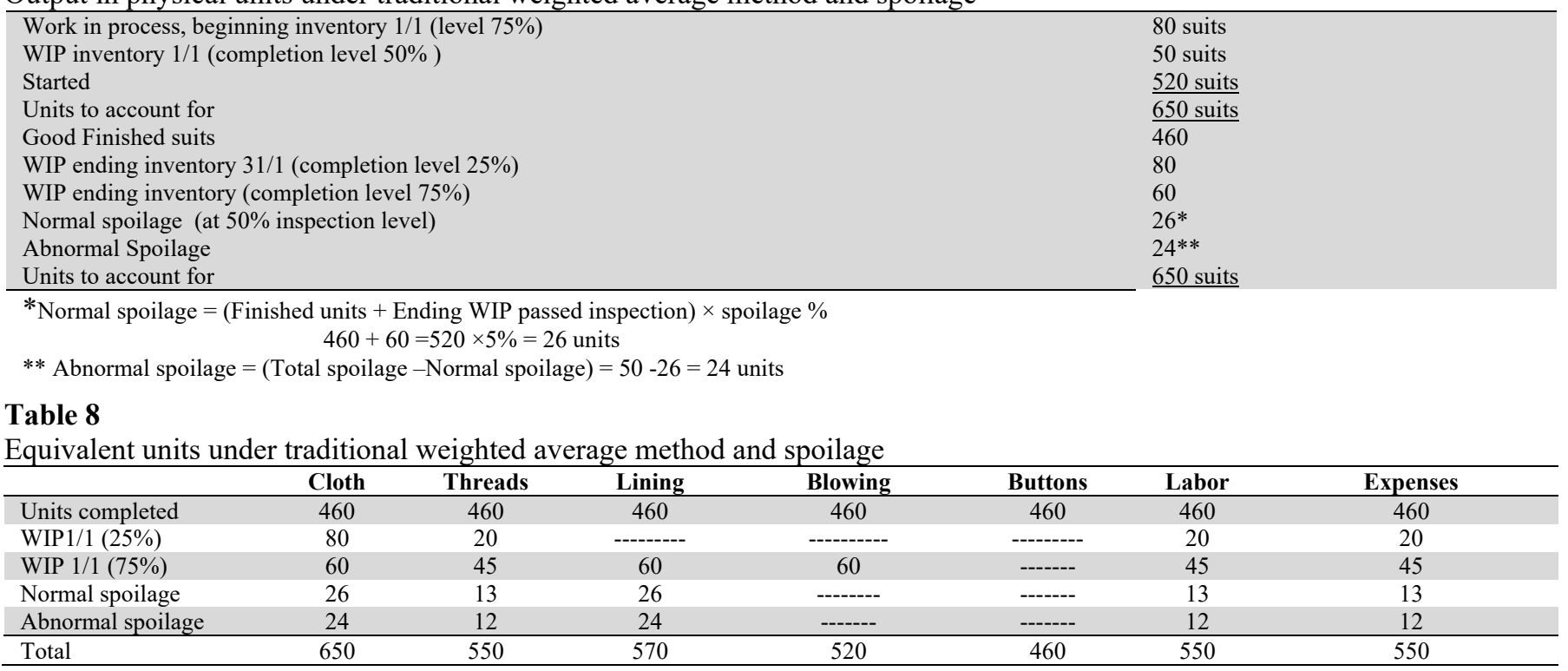

\section{Table 9}

Cost to account for and the cost per unit under traditional weighted average method and spoilage

\begin{tabular}{|c|c|c|c|c|c|c|c|c|}
\hline & Cloth & Threads & Lining & Blowing & Buttons & Labor & Expenses & Total \\
\hline WIP $1 / 1(50 \%)$ & 1224 & 60 & 136 & --------- & -------- & 1120 & 810 & 3350 \\
\hline Current cost & 18200 & 2325 & 1760 & 1320 & 1840 & 23250 & 13950 & 62645 \\
\hline $\begin{array}{l}\text { Total cost/ } \\
\text { equiv units }\end{array}$ & $\begin{array}{l}22,944 / \\
650= \\
\$ 35.30\end{array}$ & $\begin{array}{l}2615 / \\
550= \\
\$ 4.75\end{array}$ & $\begin{array}{l}2160 / \\
570= \\
\$ 3.79\end{array}$ & $\begin{array}{l}1580 / \\
520= \\
\$ 3.04\end{array}$ & $\begin{array}{l}1840 / \\
460= \\
\$ 4.00\end{array}$ & $\begin{array}{l}26399 / \\
550= \\
\$ 48.00\end{array}$ & $\begin{array}{l}15796 / \\
550= \\
\$ 28.72\end{array}$ & $\underline{73,334}$ \\
\hline Cost per unit & & & & & & & & \\
\hline
\end{tabular}

Total cost of normal spoilage $=$ normal spoilage equivalent units $\times$ cost per equivalent unit.

$$
26 \times 35.30+13 \times 4.75+26 \times 3.79+13 \times 48+13 \times 28.72=\$ 2075.45 \text {. }
$$

Normal spoilage unit cost $=$ normal spoilage cost $/$ (units completed + Ending WIP passed inspection $50 \%$ $2075.45 /(460+60)=\$ 3.99$ per unit

Table 10

Assignment of total costs to units under traditional weighted average method and spoilage

\begin{tabular}{|c|c|c|c|c|c|c|c|c|}
\hline & Cloth & Thread & Lining & Blowing & Button & Labor & Expense & Total \\
\hline $\begin{array}{l}\text { Cost of good units c } \\
\text { Add normal spoilag } \\
\text { Total Cost of good }\end{array}$ & $\begin{array}{l}\text { leted before } \\
\text { good units co } \\
\text { completed }\end{array}$ & $\begin{array}{l}\text { ng normal s } \\
\text { eted }(460 \times\end{array}$ & $\begin{array}{l}\text { e }(460 \times \$ \\
\text { 9) }\end{array}$ & & & & & $\begin{array}{r}\$ 58,696.00 \\
\frac{1835.40}{\$ 60,531.40}\end{array}$ \\
\hline $\begin{array}{l}\text { WIP 31/1 (25\%) } \\
\text { WIP 31/1 (75\%) }\end{array}$ & $\begin{array}{l}80 \times 35.30 \\
60 \times 35.30\end{array}$ & $\begin{array}{l}20 \times 4.75 \\
45 \times 4.75\end{array}$ & $60 \times 3.79$ & $60 \times 3.04$ & ----- & $\begin{array}{l}20 \times 48.00 \\
45 \times 48.00\end{array}$ & $\begin{array}{l}20 \times 28.72 \\
45 \times 28.72\end{array}$ & $\begin{array}{r}4453.32 \\
6193.61\end{array}$ \\
\hline Normal spoilage & & & & & & & & $239.40 *$ \\
\hline Abnormal spoilage & $24 \times 35.30$ & $12 \times 4.75$ & $24 \times 3.79$ & & & $12 \times 48.00$ & $12 \times 28.72$ & 1915.80 \\
\hline
\end{tabular}

*Normal spoilage cost is added to ending WIP units that passed 50\% inspection level (60 units $\times \$ 3.99=\$ 239.40)$.

** Difference in total figures is due to rounding.

\subsubsection{Traditional FIFO Method of Process Costing and Spoilage}

This method is more accurate than the previous method in determining total production cost, as it does not neglect the level of completion at which WIP beginning inventory reached. However, as for determining normal spoilage units, FIFO method uses the same formula used in the weighted average method.

Normal spoilage units $=$ good production units $\mathrm{x}$ normal spoilage percentage
Good production units $=$ good units completed + ending (WIP) passed inspection. 
Although the FIFO method does not neglect WIP beginning inventory level reached when determining good unit production cost, it neglects considering it when calculating normal spoilage units. Thus, similar to the weighted average method, the units and cost of the normal spoilage would be unrealistic because it considers all beginning WIP as part of good units completed regardless if it passed inspection point in the prior period. The five-step procedure for process costing, with slight modifications to accommodate normal and abnormal spoilage under FIFO method is illustrated and presented in Table 11 as follows.

\section{Table 11}

Output in physical units under traditional FIFO method and spoilage

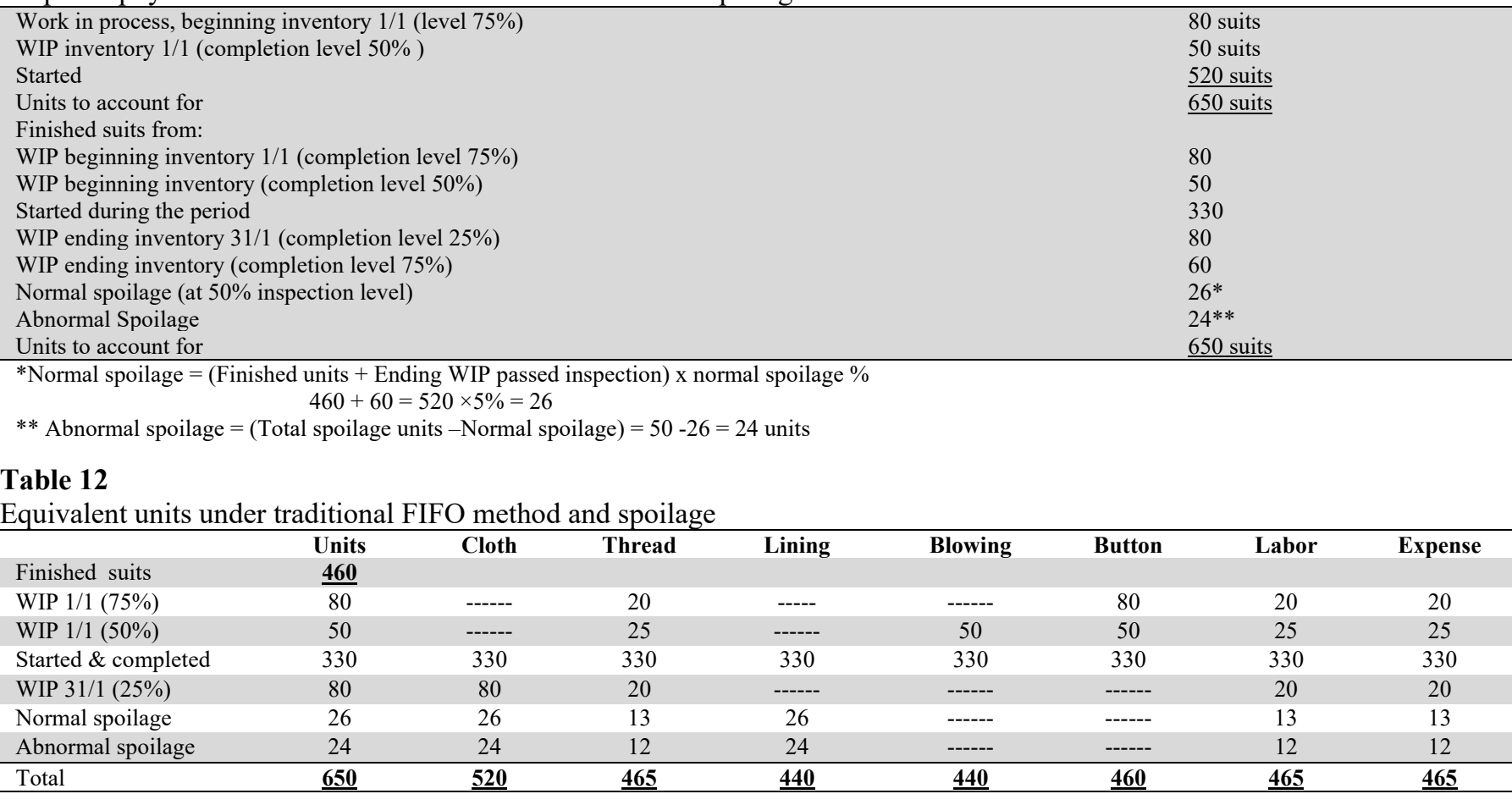

Table 13

Cost to account for and the cost per unit under traditional FIFO method and spoilage

\begin{tabular}{|c|c|c|c|c|c|c|c|c|}
\hline & Cloth & Threads & Lining & Blowing & Buttons & Labor & Expenses & Total \\
\hline WIP $1 / 1(75 \%)$ & & & & & & & & $\$ 7339$ \\
\hline Current cost & $\$ 18200$ & 2325 & 1760 & 1320 & 1840 & 23250 & 13950 & 62645 \\
\hline Total cost/ & $18,200 /$ & $2325 /$ & $1760 /$ & $1320 /$ & 1840 & $23250 /$ & $13950 /$ & $\underline{73,334}$ \\
\hline Cost per unit & $\$ 35.00$ & $\$ 5.00$ & $\$ 4.00$ & $\$ 3.00$ & $\$ 4.00$ & $\$ 50.00$ & $\$ 30.00$ & $\$ 131.00$ \\
\hline Normal spoilage & $26 \times \$ 35$ & $13 \times \$ 5$ & $26 \times \$ 4$ & - & - & $13 \times \$ 50$ & $13 \times \$ 30$ & 2119 \\
\hline Normal spoilage c & nit $=2119 /$ & $=\$ 4.075$ & & & & & & \\
\hline
\end{tabular}

Table 14

Assignment of total costs to units under traditional FIFO method and spoilage

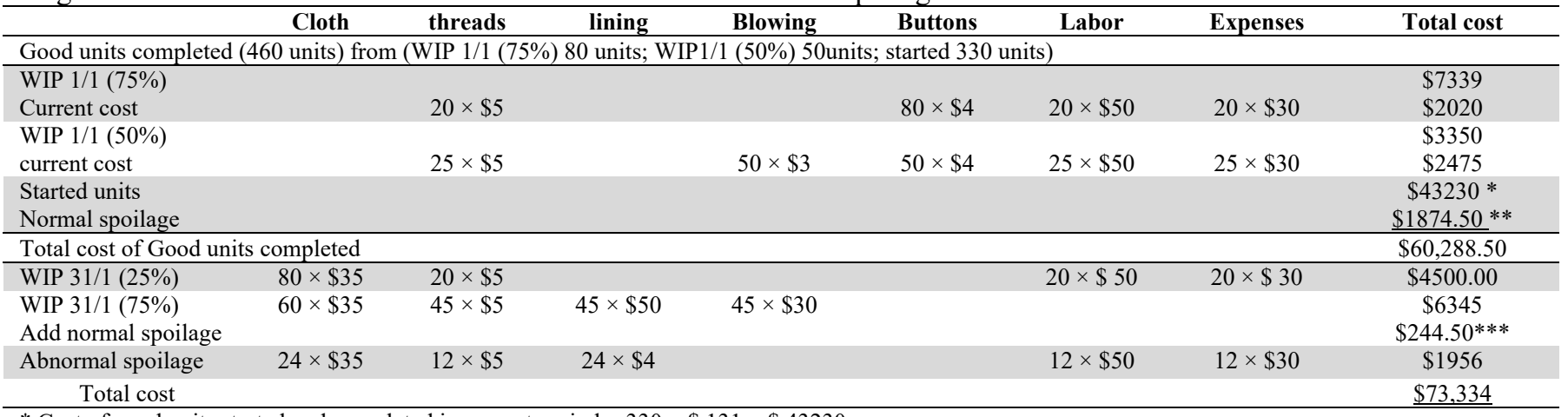

* Cost of good units started and completed in current period $=330 \times \$ 131=\$ 43230$.

$* *$ Normal spoilage cost added to good units completed $=460 \times \$ 4.075=\$ 2185.00$.

$* * *$ Normal spoilage cost added to WIP $31 / 1$ passed 50\% inspection $=60 \times \$ 4.075=\$ 244.50$. 


\subsubsection{The proposed method to account for spoilage (FIFO method)}

Similar to other methods, the units of normal spoilage under the proposed method is calculated by multiplying the percentage of normal spoilage by good units of production and apply the FIFO method for determining production cost. However, the difference between the proposed method and previous methods is twofold. First, determining normal spoilage units and the number of good units of production, the proposed method, contrary to traditional methods, includes only finished goods from beginning WIP not reached inspection level in the prior period and excludes beginning WIP reached and passed inspection in the prior period. The adjusted formula for determining normal spoilage is:

Normal spoilage units $=$ good production units $* \times$ normal spoilage percentage.

*Good production units = finished units from beginning WIP not reached or passed inspection point in the prior period + units started \& completed in the current period + ending WIP passed inspection.

Thus, the proposed method takes into account only beginning WIP not reached the level of the inspection in the prior period. It excludes beginning WIP that has reached and passed the level of the inspection in the prior period on the bases that it was considered in the previous period as ending work in process units that have arrived and passed the level of inspection, and was included in previous period for determining normal spoilage. Thus, it must not be accounted for in the current period, otherwise, it would be double-counted and would overstate normal spoilage and accordingly increase the cost of good units manufactured. To illustrate, the output of physical units and equivalent units and costs per unit including normal and abnormal spoilage under the proposed method are presented in Tables 15, 16 and 17.

\section{Table 15}

Output in physical units under the proposed method

\begin{tabular}{|c|c|}
\hline Work in process, beginning inventory $1 / 1$ (level $75 \%)$ & 80 suits \\
\hline WIP inventory $1 / 1$ (completion level 50\% ) & 50 suits \\
\hline Units to account for & 650 suits \\
\hline \multicolumn{2}{|l|}{ Finished suits from: } \\
\hline WIP beginning inventory (completion level 50\%) & 50 \\
\hline Started during the period & 330 \\
\hline WIP ending inventory $31 / 1$ (completion level $25 \%$ ) & 80 \\
\hline Abnormal Spoilage & $31 * *$ \\
\hline Units to account for & 650 suits \\
\hline
\end{tabular}

Table 16

Equivalent units under the proposed method

\begin{tabular}{|c|c|c|c|c|c|c|c|c|}
\hline & Units & Cloth & Threads & Lining & Blowing & Buttons & Labor & Expense \\
\hline Good suits completed & $\underline{460}$ & & & & & & & \\
\hline WIP $1 / 1(75 \%)$ & $\overline{80}$ & ----- & 20 & ----- & ----- & 80 & 20 & 20 \\
\hline WIP $1 / 1(50 \%)$ & 50 & & 25 & ----- & 50 & 50 & 25 & 25 \\
\hline Started and completed & 330 & 330 & 330 & 330 & 330 & 330 & 330 & 330 \\
\hline WIP 31/1 (25\%) & 80 & 80 & 20 & ----- & ----- & ----- & 20 & 20 \\
\hline WIP 31/1 (75\%) & 60 & 60 & 45 & 60 & 60 & --- & 45 & 45 \\
\hline Normal spoilage $50 \%$ & 19 & 19 & 9.5 & 19 & ------ & ----- & 9.5 & 9.5 \\
\hline Abnormal spoilage & $\underline{31}$ & $\underline{31}$ & $\underline{15.5}$ & $\underline{31}$ & ----- & ----- & $\underline{15.5}$ & 15.5 \\
\hline Total equivalent units & 650 & 520 & 465 & 440 & 440 & 460 & 465 & 465 \\
\hline
\end{tabular}

Table 17

Cost to account for and the cost per unit under the proposed method

\begin{tabular}{|c|c|c|c|c|c|c|c|c|}
\hline $\begin{array}{l}\text { WIP } 1 / 1(75 \%) \\
\text { WIP } 1 / 1(50 \%)\end{array}$ & Cloth & Threads & Lining & Blowing & Buttons & Labor & Expenses & $\begin{array}{c}\text { Total } \\
\$ 7339 \\
3350\end{array}$ \\
\hline Current cost & $\$ 18200$ & 2325 & 1760 & 1320 & 1840 & 23250 & 13950 & 62645 \\
\hline Total cost/ & $18,200 /$ & $2325 /$ & $1760 /$ & $1320 /$ & 1840 & $23250 /$ & $13950 /$ & 73,334 \\
\hline equivalent units & 520 & 465 & 440 & 440 & 460 & 465 & 465 & \\
\hline Cost per unit & $\$ 35.00$ & $\$ 5.00$ & $\$ 4.00$ & $\$ 3.00$ & $\$ 4.00$ & $\$ 50.00$ & $\$ 30.00$ & $\$ 131.00$ \\
\hline \multicolumn{9}{|c|}{$\begin{array}{l}\text { Total cost of normal spoilage }=19 \times 35.00+9.5 \times 5.00+19 \times 4.00+9.5 \times 50+9.5 \times 30=\$ 1548.50 \\
\text { spoilage cost per unit }=\text { total cost of normal spoilage } / \text { good finished suits (from started }+ \text { beginning WIP not passed inspection in prior period) }+ \text { ending WIP } \\
\text { passed inspection in current period }+ \text { abnormal spoilage }=1548.5 / 421(330+0+60+31)=\$ 3.678 .\end{array}$} \\
\hline
\end{tabular}


These tables show that of the 50 units of production spoilage, normal spoilage counts to 19 units instead of 26 units counted in the previous methods, and the total normal spoilage cost decreased under the proposed method to $\$ 1548.50$ instead of $\$ 2119$ which represents a significant reduction of approximately $27 \%$. In addition, abnormal spoilage units increased to 31 units instead of 24 units representing a significant increase of $29 \%$. As indicated earlier, this significant reduction of normal spoilage would be reflected in the cost of good units manufactured and accordingly enhance the competitiveness of suits factory under study.

The second main difference between the proposed method and previous methods relates to assigning normal spoilage cost. Under the previous methods, normal spoilage cost is added to good units completed and ending WIP passed inspection. However, the proposed method, in addition to adding normal spoilage to good units and ending WIP passed inspection, part of normal spoilage is added to abnormal spoilage cost. The rationale for such treatment is that abnormal spoilage units are assumed not to be present in efficient manufacturing environment since it is not inherent in the production process. Thus, under an efficient production environment these units are assumed to be good units to account for, and thus, would absorb part of normal spoilage cost (Yame et al., 2016). To illustrate, Table 18 presents an assignment of production cost to good units completed, ending WIP units passed inspection and abnormal spoilage. As can be noted from Table 18, abnormal spoilage cost increased to \$2640.51 instead of $\$ 1956$ in previous FIFO method representing a significant increase of 35\%. This significant increase in abnormal spoilage cost is recognized in the income statement as loss from abnormal production spoilage, and would negatively affect operating income thus, makes management pay more attention to manage, control and eliminate abnormal spoilage in the future. Also, Table 18 shows that both beginning periods WIP units have passed inspection point (50\% completion level) in prior period thus good units completed and transferred from them were not assigned any normal spoilage cost. Normal spoilage cost is added only to good units completed from started units in the current period (330 units).

Table 18

Assignment of production cost to units under the proposed method

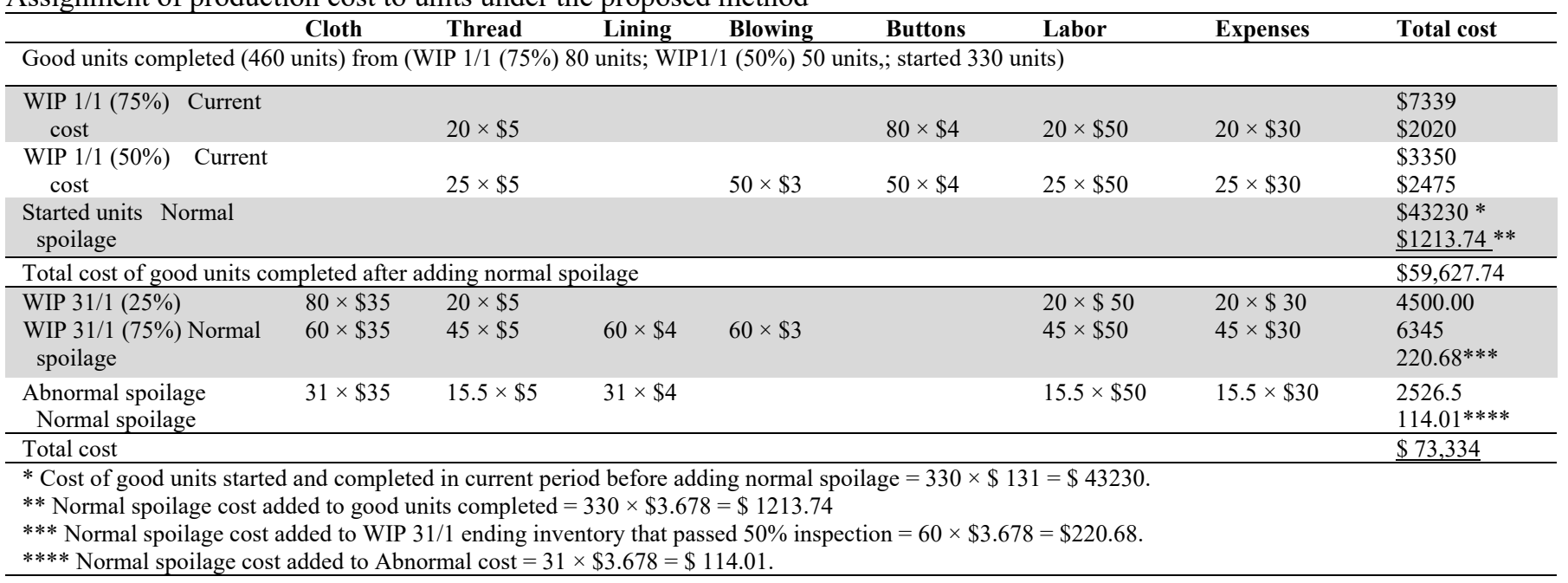

\section{Conclusion and Recommendation}

The current study proposes a new method to account for production spoilage in process costing system, not previously discussed in cost accounting literature and/or textbooks (e.g., Horngren et al., 2012; Drury 2018). It differs from other methods discussed in cost accounting textbooks in determining normal spoilage units and assignment of production cost. The study used data from a real factory that makes men's suits for the month of January 2018 to illustrate and explain the proposed method and its impact on cost reduction. Table 19 presents a summary of the key results obtained from applying the proposed method compared to other traditional methods of process costing system.

Table 19

Comparison of Key Figures between traditional methods and the proposed method

\begin{tabular}{lcccc}
\hline & $\begin{array}{c}\text { Traditional weighted } \\
\text { average (Ignore } \\
\text { spoilage) }\end{array}$ & $\begin{array}{c}\text { Traditional weighted } \\
\text { average and spoilage }\end{array}$ & $\begin{array}{c}\text { Traditional FIFO and } \\
\text { spoilage }\end{array}$ & Proposed \\
Normal Spoilage & 0 & $\$ 2075$ & $\$ 2429$ & method (FIFO) \\
Abnormal spoilage & 0 & $\$ 1915$ & $\$ 1956$ & $\$ 1548$ \\
Cost of good units & $\$ 61,998.80$ & $\$ 60,531.40$ & $\$ 60,288.50$ & $\$ 2640$ \\
Ending WIP & $\$ 11,333$ & $\$ 10886$ & $\$ 11,290$ & $\$ 59,627.74$ \\
\hline
\end{tabular}


The obtained results prove the study proposition that traditional methods to account for production spoilage overstate normal spoilage cost, and hides or understate actual abnormal production spoilage. The results also prove that the proposed method is able to reduce normal spoilage cost by $27 \%$, compared to traditional methods. Thus, the significant reduction in normal spoilage results also in a cost reduction of good units manufactured and accordingly enhances a firm's competitiveness.

In addition, the abnormal spoilage cost under the proposed method increased by $35 \%$ thus, it would be better noticeable by management to focus on, control and eliminate. Hiding, burying or underestimating these costs in finished production cost would make them not noticeable by management to control which will have a detrimental effect on the competitiveness of manufacturing firms.

The study recommends that manufacturing firms adopt the proposed method to account for production spoilage as it is more accurate and results in product cost reduction and helps management to better focus on production spoilage and take corrective actions to control and eliminate. The study also recommends that cost accounting lecturers and students use the compressive case study material from a real manufacturing context, with its detailed cost data, assumptions and different completion levels of beginning WIP to better appreciate and understand the accounting for production spoilage under process costing methods in complex manufacturing setting. The majority of cost accounting examples and illustrations in cost accounting texts provide straight forward and simple assumptions regarding level of completion of material and conversion cost while in reality, as in the case study of the current study, different classes of material and conversion costs have different levels of completion.

Finally, the limitation of this study is lack of cost accounting literature and research on production spoilage and innovative and cost accounting ideas and methods, except what is in cost accounting textbooks or applied research literature (e.g.; activity based costing, target costing). Thus, future researchers could build and adapt or improve the proposed method and come up with other innovative cost accounting methods and systems that would overcome deficiencies of traditional cost accounting, and enhance firms' cost management and competitiveness in the market.

\section{References}

Abdusalomova, N. (2017). Cost accounting and financial health: Analysis of cost reduction policy effect in selected enterprises of metallurgy industry in Uzbekistan. International Journal of Management Science and Business Administration, 3(3).

Dereli, D. (2015). Innovation management in global competition and competitive advantage, Procedia: Social and Behavioral sciences, 195

Drury, C. (2018). Management and Cost Accounting. 10 $0^{\text {th }}$ edition. New Jersey: Cengage.

Johnson, H., \& Kaplan R. (1987). Relevance lost: The rise and fall of management accounting. M A: Harvard University Press.

Evans, J., \& Lindsay, W. (2005). The management and control of quality. $6^{\text {th }}$ edition. Ohio: Thompson.

Hervas, J., \& Dalmau, J. (2006). How to measure IC in clusters: Empirical evidence, Journal of Intellectual Capital, 7(3).

Horngren, C., Datar, S., \& Rajan, N. (2012). Cost accounting: A managerial emphasis. $14^{\text {th }}$ ed. Pearson Higher Education AU.

Kogan, K., López-Ortiz, A., Nikolenko, S. I., \& Sirotkin, A. V. (2017). The impact of processing order on performance: A taxonomy of semi-FIFO policies. Journal of Computer and System Sciences, 88, 220-235.

Kolus, A., Wells, R., \& Neumann, P. (2018). Production quality and human factors engineering: a systematic review and theoretical framework. Applied Ergonomics, 73, 55-89.

Lukka, K., \& Granlund, M. (1996). Cost accounting in Finland: Current practice and trends of development. European Accounting Review, 5(1).

Mahmood, S. \& Kureshi, N. (2015). Literature review on the quantification of hidden cost of poor quality in the historical perspective. Journal of Quality and Technology Management. 11(1), 1-24.

Malta, J., \& Cunha, P. (2011). A new approach for cost modelling and performance evaluation within operations planning. CIRP Journal of Manufacturing Science and Technology, 4(3).

Manohar, H. M., \& Appaiah, S. (2017). Stabilization of FIFO system and Inventory Management. International Research Journal of Engineering and Technology, 4(6).

Melendez, K., Davila, A., \& Melgar, A. (2019). Literature review of the measurement in innovation management, Journal of Technology Management and Innovation, 4(2).

Oker, F. (2002). A survey of the product costing practice of large manufacturing companies in Turkey. Review of Social Economic and Administrative Studies, (1).

Pike, R., Tayles, M., \& Mansor, N. (2011). Activity-based costing user satisfaction and type of system: A research note. The British Accounting Review, 43(1).

Rao, A., Carr, L., Dambolena, I., Kopp, R., Martin, J., Rafii, F., \& Schelesinger, P. (2010). Total quality management: Across functional perspective. NY: Wiley.

Yame, A., Ali, A., Jawad, B., Nasser, D., \& Abro, S. (2016). Optimization of lean methodologies in the textile industry using design of experiments. International Journal of Materials and Textile Engineering, 10(9), 3218-3222. 
Zawawi, N., \& Hough, Z. (2010) Research in management accounting innovations: An overview of its recent developments. Qualitative Research in Accounting and Management, 7.

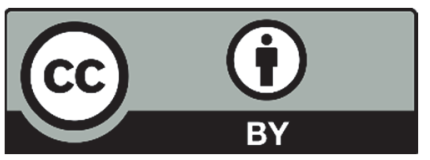

(C) 2021 by the authors; licensee Growing Science, Canada. This is an open access article distributed under the terms and conditions of the Creative Commons Attribution (CC-BY) license (http://creativecommons.org/licenses/by/4.0/). 